\title{
Desempenho e consumo de matéria seca de bovinos sob suplementação protéico- energética, durante a época de transição água-seca
}

\author{
[Protein and energy supplementation of steers during the transition of the wet to the dry season] \\ F.A. Barbosa ${ }^{1,4}$, D.S. Graça ${ }^{2}$, W.E. Maffei ${ }^{1}$, F.V. Silva Júnior ${ }^{3}$, G.M. Souza ${ }^{4}$ \\ ${ }^{1}$ Aluno de pós-graduação - EV-UFMG \\ ${ }^{2}$ Escola de Veterinária - UFMG \\ Caixa Postal 567 \\ 30123-970 - Belo Horizonte, MG \\ ${ }^{3}$ Engenheiro agrônomo - autônomo \\ ${ }^{4}$ Instituto de Tecnologia Brasil Pecuária - Belo Horizonte, MG
}

\begin{abstract}
RESUMO
Avaliou-se o efeito da suplementação protéico-energética em dois níveis de ingestão diária, 0,17 e $0,37 \%$ do peso vivo médio, sobre o no desempenho e consumo de matéria seca por bovinos, em pastagens de Brachiaria brizantha cv. Marandu. Para avaliação do desempenho foram utilizados 42 novilhos (Holandês x Gir - HG), com média de $211 \mathrm{~kg}$ de peso vivo inicial (PVI) e para a avaliação do consumo de matéria seca total (CMST) e de forragem (CMSF) foram usados 15 novilhos inteiros HG, com 239kg de PVI. Os tratamentos foram: SM - controle; SUP1 - suplementação protéico-energética com ingestão média diária de $0,17 \%$ do peso vivo e SUP2 - suplementação protéico-energética com ingestão média diária de $0,37 \%$ do peso vivo (PV). Os valores do CMSF foram de 2,6, 2,4 e 2,3\% PV, e os de CMST 2,6, 2,6 e 2,6\% PV, para SM, SUP1 e SUP2, respectivamente. Esses valores não diferiram entre si $(\mathrm{P}>0,05)$. A suplementação protéico-energética proporcionou maior ganho de peso, $0,54,0,66 \mathrm{e} 0,75 \mathrm{~kg} /$ cabeça/dia para SM, SUP1 e SUP2, respectivamente.
\end{abstract}

Palavras-chave: bovino, Brachiaria brizantha, pasto, suplementação

\begin{abstract}
The effect of two levels of daily intake $(0.17 \%$ and $0.37 \%$ of live weight) of protein and energy supplementation on weight gain and on dry matter intake of bulls grazing Brachiaria Brizantha $c v$. Marandu grass was evaluated. Forty two bulls (Holstein $x$ Gir - HG), averaging $211 \mathrm{~kg}$ initial LW, were used in the performance trial, and 15 HG steers, averaging $239 \mathrm{~kg}$ initial LW, for evaluation of total dry matter intake (TDMI) and forage dry matter intake (FDMI). The treatments were: MS - mineral supplementation, SUP1 - protein and energy supplementation with an average daily intake of $0.17 \%$ of the live body weight, and SUP 2 - protein and energy supplementation with an average daily intake of $0.37 \%$ of the live body weight. The average FDMI intakes were 2.6, 2.4, and $2.3 \%$ of the $L W$, for $M S$, SUP1 and SUP2, respectively. The average TDMI intakes were 2.6, 2.6, and 2.6\% for MS, SUP1, and SUP2, respectively. Protein and energy supplementation increased weight gain from $0.54 \mathrm{~kg} /$ day in the MS treatment to 0.66 and $0.75 \mathrm{~kg} /$ day for SUP1 and SUP2, respectively.
\end{abstract}

Keywords: cattle, Brachiaria brizantha, pasture, supplementation

Recebido em 10 de julho de 2006

Aceito em 8 de janeiro de 2007

E-mail: fabianoalvim@superig.com.br 


\section{INTRODUÇÃO}

O consumo de matéria seca por bovinos em pasto e seu desempenho estão relacionados com a quantidade e qualidade da forragem disponível. Segundo o NRC (Nutrient..., 1996), pastagens com menos de $2.000 \mathrm{~kg}$ de matéria seca (MS) por hectare ensejam menor consumo de pasto e aumento do tempo de pastejo. O consumo também pode cair quando a forragem ingerida tiver menos que 6 a $8 \%$ de proteína bruta na MS.

A estratégia da suplementação protéicoenergética-mineral de bovinos no pasto é usada quando a forragem é deficiente em nutrientes específicos, visando melhorar a digestibilidade da forragem disponível para maximizar o seu consumo.

Segundo Euclides (2000), os trabalhos com forrageiras tropicais têm demonstrado que a produção animal não está correlacionada com o total de forragem disponível nas pastagens com grande acúmulo de matéria seca morta. No entanto, ela está assintoticamente correlacionada com a disponibilidade de matéria seca verde (MSV). Os ganhos diários, durante 12 meses, foram de até $0,5 \mathrm{~kg}$ para uma disponibilidade de MSV de $1.000 \mathrm{~kg} /$ ha para o gênero Brachiaria. Acima desses valores de disponibilidade de MSV o ganho diário não foi alterado.

Mesmo na estação chuvosa, quando, aparentemente, as pastagens podem atender às demandas nutricionais dos animais, a suplementação de proteína e energia pode ser benéfica. Paulino et al. (2002a) verificaram que a suplementação de proteína durante a estação das águas proporcionou ganho adicional diário de 200-300g/animal.

O objetivo do trabalho foi avaliar o efeito da suplementação protéico-energética no desempenho e consumo dos bovinos, na fase de recria, durante a época de transição água-seca, em pastagens de Brachiaria brizantha cv. Marandu.

\section{MATERIAL E MÉTODOS}

O trabalho foi realizado na Fazenda Invernada, localizada no município de Cachoeira da Prata MG, região metropolitana de Belo Horizonte, em área experimental composta de três piquetes de
B. brizantha cv. Marandu, cada um com 14 hectares (ha) efetivos.

Foram usados, como unidade experimental, 42 novilhos não castrados, cruzados (Holandês $\mathrm{x}$ Gir), com 12 meses de idade média, $211 \mathrm{~kg}$ de peso vivo médio inicial e distribuídos aleatoriamente em três tratamentos. E, ainda, mais 66 novilhos cruzados e não castrados, com peso vivo médio inicial de $218 \mathrm{~kg}$, distribuídos aleatoriamente nos três tratamentos para consumirem o excedente das pastagens. Foi adotado o sistema de pastejo contínuo com taxa de lotação variável; a taxa de lotação média foi de 1,2UA/ha.

O período experimental foi de 15 de fevereiro a 14 de junho de 2003, sendo os 14 dias iniciais de adaptação. Os novilhos foram pesados a cada 21 dias, coincidindo com a data de rodízio dos animais nas pastagens. A pesagem inicial e final foi precedida de 14 horas de jejum absoluto de água e alimento; nas pesagens intermediárias não houve jejum prévio.

A amostragem de massa forrageira da pastagem foi feita nos meses de março, maio e junho de 2003, conforme McMeniman (1997). Após a pesagem, foi feita homogeneização das amostras por piquete e dessas retiradas duas amostras compostas, uma para análise de disponibilidade total e outra para determinação do percentual das frações matéria seca verde (MSV) e matéria seca morta (MSM).

As amostras de forragem, colhidas pelo método de pastejo simulado, foram congeladas a $-20^{\circ} \mathrm{C}$, e, à época, descongeladas à temperatura ambiente, secas a $65^{\circ} \mathrm{C}$ por 72 horas, em estufa de ventilação forçada, moídas em moinho de martelo em peneira de $1 \mathrm{~mm}$.

A avaliação do consumo foi feita nos meses de março e maio de 2003, utilizando-se o óxido crômico, como indicador externo. As amostras de fezes foram congeladas à $-20^{\circ} \mathrm{C}$ e, posteriormente, descongeladas à temperatura ambiente, secas a $65^{\circ} \mathrm{C}$ por 72 horas, em estufa de ventilação forçada, moídas e analisadas quanto ao teor de cromo. $\mathrm{O}$ cromo foi quantificado segundo a técnica de Williams et al. (1962) e descrita por Silva e Queiroz (2002), 
utilizando-se espectrofotômetro de absorção atômica.

A digestibilidade in vitro da matéria seca (DIVMS) da forragem e dos suplementos foi obtida segundo Tilley e Terry (1963). A excreção fecal diária (EF) e a matéria seca ingerida por dia (MSI) foram calculadas pelas fórmulas de Smith e Reid (1955).

As amostras de forragem do pastejo simulado e dos suplementos foram analisadas de acordo com Silva e Queiroz (2002) quanto ao seu teor de matéria seca total (MS), proteína bruta (PB), extrato etéreo (EE), digestibilidade in vitro da matéria seca (DIVMS), cinzas, cálcio $(\mathrm{Ca})$, fósforo $(\mathrm{P})$, fibra em detergente neutro (FDN), fibra em detergente ácido (FDA) e nitrogênio insolúvel em detergente neutro (NIDN). Cobre, cobalto, zinco e manganês foram quantificados utilizando-se espectrofotômetro de absorção atômica, e a quantidade de carboidratos não fibrosos (CNF) calculada segundo Hall (2000). Os suplementos protéico-energéticos foram oferecidos diariamente às 10 horas da manhã em cochos apropriados. O consumo do suplemento mineral foi medido a cada 21 dias. Os suplementos visavam atender o mínimo de $40 \%$ da necessidade protéica de um novilho inteiro de $250 \mathrm{~kg}$ de peso vivo (PV), que, em termos absolutos, significavam fornecer de 0,60 a $0,75 \mathrm{~kg}$ de $\mathrm{PB} / \mathrm{dia}$ (Nutrient..., 1996) com o objetivo de proporcionar ganhos diários de peso entre 0,7 e $1,0 \mathrm{~kg}$.

O delineamento experimental foi ao acaso, com três tratamentos (Tab.1 e 2): controle (SM), suplementação protéico-energética com ingestão de $0,17 \%$ do peso vivo médio (SUP1) e suplementação protéico-energética com ingestão de $0,37 \%$ do peso vivo médio (SUP2).

Tabela 1. Composição centesimal do suplemento mineral (SM) e suplementos protéico-energéticos (SUP1 e SUP2) e custo do produto (R $\$ / \mathrm{kg}$ )

\begin{tabular}{lccc}
\hline & SM & SUP1 & SUP2 \\
\hline Farelo de soja - \% & - & 60 & 15 \\
Polpa cítrica - \% & - & 13 & 63 \\
Uréia - \% & - & 11 & 7 \\
Melaço em pó - \% & - & 7 & 10 \\
Suplemento mineral - \% & - & 4,6 & 2,6 \\
Cloreto de sódio - \% & 49,0 & 3,2 & 1,6 \\
Fosfato bicálcico & 41,1 & - & - \\
Calcário calcítico & 9,203 & - & - \\
Sulfato de cobre & 0,41 & - & - \\
Sulfato de manganês & 0,12 & - & - \\
Sulfato de cobalto & 0,007 & - & - \\
Oxido de zinco & 0,16 & - & - \\
Sulfato de Amônio - \% & - & 1,2 & 0,8 \\
\hline TOTAL - \% & 100 & 100 & 100 \\
\hline R $/$ kg & 0,640 & 0,595 & 0,422 \\
\hline
\end{tabular}

Para avaliação do consumo foram usados cinco novilhos por tratamento, com peso vivo inicial médio de $239 \mathrm{~kg}$, em delineamento inteiramente ao acaso, com três tratamentos, SM, SUP1 e SUP2. Os dados foram analisados pelo método dos quadrados mínimos, por meio do procedimento PROC GLM do pacote estatístico SAS (User's..., 1990). Para a comparação entre médias, adotou-se o teste SNK $(\mathrm{P} \leq 0,05)$

Quanto ao desempenho, adotou-se o mesmo método dos quadrados mínimos, por meio do mesmo procedimento. Os animais usados para avaliar o consumo também o foram para estudar o desempenho. Para a comparação entre as médias, adotou-se o teste $\mathrm{t}$ de Student $(\mathrm{P} \leq 0,05)$. $\mathrm{O}$ modelo matemático, neste caso, foi:

$Y_{i j}=\mu+T_{i}+P I_{j}+e_{i j}$, em que:

$\mathrm{Y}_{\mathrm{ij}}=$ ganho do animal j pertencente ao tratamento i; $\mu=$ efeito médio;

$\mathrm{T}_{\mathrm{i}}=$ efeito fixo do tratamento $\mathrm{i},(\mathrm{i}=1,2,3)$;

$\mathrm{PI}_{\mathrm{j}}=$ covariável peso inicial do animal $\mathrm{j}$.

$\mathrm{e}_{\mathrm{ij}}=$ erro aleatório associado a cada animal. 
Tabela 2. Valores de matéria seca total (MS), proteína bruta (PB), digestibilidade in vitro da matéria seca (DIVMS), nutrientes digestíveis totais (NDT), fibra em detergente neutro (FDN), fibra em detergente ácido (FDA), nitrogênio insolúvel em detergente neutro (NIDN), extrato etéreo (EE), carboidratos não fibrosos $(\mathrm{CNF})$, cinzas, cálcio $(\mathrm{Ca})$, fósforo $(\mathrm{P})$, cobre $(\mathrm{Cu})$, cobalto $(\mathrm{Co})$, manganês $(\mathrm{Mn})$ e zinco $(\mathrm{Zn})$ expressos na base da matéria seca do suplemento mineral (SM) e suplementos protéico-energéticos (SUP1 e SUP2)

\begin{tabular}{|c|c|c|c|}
\hline & SM & SUP1 & SUP2 \\
\hline MS (\%) & - & 86,12 & 86,59 \\
\hline PB (\%) & - & 69,44 & 39,19 \\
\hline DIVMS (\%) & - & 85,95 & 86,80 \\
\hline $\operatorname{NDT}(\%)^{1}$ & - & 74,62 & 79,23 \\
\hline FDN (\%) & - & 15,71 & 21,6 \\
\hline FDA $(\%)$ & - & 10,10 & 17,16 \\
\hline $\operatorname{NIDN}(\%)^{2}$ & - & 12,06 & 16,43 \\
\hline EE $(\%)$ & - & 3,02 & 3,31 \\
\hline CNF (\%) & - & 3,20 & 28,74 \\
\hline Cinzas $(\%)$ & - & 17,01 & 13,60 \\
\hline $\mathrm{Ca}(\%)$ & 12,8 & 2,19 & 2,37 \\
\hline $\mathrm{P}(\%)$ & 7,4 & 1,15 & 0,58 \\
\hline $\mathrm{Cu}(\mathrm{mg} / \mathrm{kg})$ & 1028 & 104 & 63 \\
\hline Co $(\mathrm{mg} / \mathrm{kg})$ & 14 & 5 & 5 \\
\hline $\mathrm{Mn}(\mathrm{mg} / \mathrm{kg})$ & 312 & 128 & 84 \\
\hline $\mathrm{Zn}(\mathrm{mg} / \mathrm{kg})$ & 1177 & 535 & 324 \\
\hline
\end{tabular}

${ }^{1}$ Estimado pela equação: NDT = DIVMS - cinzas + 1,25 EE + 1,9 (Van Soest, 1994).

${ }^{2}$ Valores expressos em \% do nitrogênio total.

\section{RESULTADOS E DISCUSSÃO}

Os resultados da matéria seca total (MST), MSV e MSM das pastagens mostraram que a quantidade de MSV foi mais alta que $1000 \mathrm{~kg} / \mathrm{ha}$, que teria favorecido o ganho diário segundo Euclides (2000). Portanto, os animais tiveram oportunidade de selecionar a pastagem, que é um fator muito importante para maximizar o consumo (Tab. 3).

Os dados da composição média das amostras de pastejo simulado são mostrados na Tab. 4. Foi observado que à medida que diminuíram os teores de PB, DIVMS e NDT, aumentaram os de FDN, FDA, NIDN, cinzas e $\mathrm{Ca}$, fato atribuído ao processo de senescência da parte aérea da forragem com aumento no teor de fibra e perda de seu valor nutritivo (Van Soest, 1994). Resultados similares foram observados por Euclides et al. (1992) para $\mathrm{PB}$, digestibilidade in vitro da matéria orgânica e FDN.

Os dados de consumo são apresentados na Tab. 5 . Não houve efeito significativo das suplementações no CMSF e no CMST em relação ao tratamento SM nas diferentes formas de expressão de consumo (\% $\mathrm{PV}$ e $\left.\mathrm{g} / \mathrm{kg} \mathrm{P}^{0,75}\right)(\mathrm{P}>0,05)$. Isto pode ser creditado à quantidade suplementada, menor que $0,4 \%$ do peso vivo, além do tipo de carboidrato fornecido, pectina, que, possivelmente, não reduziu o $\mathrm{pH}$ ruminal suficientemente para deprimir o consumo, como observado por Pordomingo et al. (1991) e Caton e Dhuyvetter (1997).

Tabela 3. Produção média de matéria seca total (MST), matéria seca verde (MSV) e matéria seca morta (MSM) por hectare de Brachiaria brizantha, de acordo com o mês

\begin{tabular}{lccc}
\hline & MST (kg/ha) & MSV (kg/ha) & MSM (kg/ha) \\
\hline Março & 7.362 & 4.313 & 3.049 \\
Maio & 6.072 & 3.301 & 2.771 \\
Junho & 5.721 & 2.421 & 3.300 \\
\hline Média & 6.385 & 3.345 & 3.040 \\
\hline
\end{tabular}


Tabela 4. Médias de proteína bruta (PB), digestibilidade in vitro da matéria seca (DIVMS), nutrientes digestíveis totais (NDT), fibra detergente neutro (FDN), fibra detergente ácido (FDA), nitrogênio insolúvel no detergente neutro (NIDN), extrato etéreo (EE), carboidratos não fibrosos (CNF), cinzas, cálcio (Ca) e fósforo (P), expressos na base da matéria seca, da Brachiaria brizantha, de acordo com o mês

\begin{tabular}{lcccc} 
& Março & Maio & Junho & Média \\
\hline PB (\%) & 6,72 & 8,07 & 5,81 & 6,87 \\
DIVMS (\%) & 55,53 & 57,67 & 49,10 & 54,10 \\
NDT (\%) & 52,79 & 54,78 & 43,74 & 50,44 \\
FDN (\%) & 65,98 & 63,60 & 67,07 & 65,55 \\
FDA (\%) & 32,03 & 31,21 & 33,81 & 32,35 \\
NIDN (\%) & 21,17 & 20,86 & 30,95 & 24,37 \\
EE (\%) & 3,76 & 3,77 & 3,33 & 3,62 \\
CNF (\%) & 15,73 & 16,80 & 13,95 & 15,49 \\
Cinzas (\%) & 9,34 & 9,50 & 11,42 & 10,09 \\
Ca (\%) & 0,47 & 0,66 & 0,88 & 0,67 \\
P (\%) & 0,17 & 0,17 & 0,16 & 0,17 \\
\hline
\end{tabular}

${ }^{1}$ Estimado pela equação: NDT $=$ DIVMS - cinzas + 1,25 EE + 1,9 (Van Soest, 1994).

${ }^{2}$ Valores expressos em \% do nitrogênio total.

O resultado de consumo de MST do tratamento SM está de acordo com o NRC (Nutrient..., 1996), que prevê um consumo de 2,5 a $2,9 \%$ do PV para novilhos com média de $235 \mathrm{~kg}$ e dietas com 45 a $55 \%$ de NDT, e próximo aos $2,5 \%$ do PV encontrados por Almeida et al. (2003) em bezerros, com PV inicial de $138 \mathrm{~kg}$, em pastagens de B. brizantha consorciada com Stylosanthes guianensis cv. Minerão, durante a época das águas. Euclides et al. (2000) observaram consumos mais elevados $(2,8 \%)$ que os do presente trabalho, em novilhos mantidos em pastagens exclusivas de $B$. brizantha, no período das águas.

Tabela 5. Médias de consumo de matéria seca de forragem (CMSF), consumo de matéria seca de suplemento (CMSS) e consumo de matéria seca total (CMST) em função dos diferentes tratamentos, em diferentes unidades $\left(\mathrm{kg} / \mathrm{dia}, \%\right.$ peso vivo $(\mathrm{PV}), \mathrm{g} / \mathrm{kg}$ de peso metabólico $\left.\left(\mathrm{P}^{0,75}\right)\right)$

\begin{tabular}{|c|c|c|c|c|}
\hline & SM & SUP1 & SUP2 & CV (\%) \\
\hline CMSF (kg/dia) & 5,71 & 5,76 & 5,92 & 20,44 \\
\hline CMSS (kg/dia) & 0,04 & 0,36 & 0,78 & \\
\hline CMST (kg/dia) & 5,75 & 6,12 & 6,70 & 19,17 \\
\hline CMSF (\% PV) & 2,59 & 2,43 & 2,34 & 11,58 \\
\hline CMSS (\% PV) & 0,01 & 0,16 & 0,31 & \\
\hline CMST (\% PV) & 2,60 & 2,59 & 2,65 & 11,47 \\
\hline CMSF $\left(\mathrm{g} / \mathrm{kg} \mathrm{\textrm {P } ^ { 0 , 7 5 }}\right)$ & 99,76 & 94,83 & 93,07 & 11,77 \\
\hline CMSS $\left(\mathrm{g} / \mathrm{kg} \mathrm{P}^{0,75}\right)$ & 0,59 & 6,16 & 12,33 & \\
\hline $\operatorname{CMST}\left(\mathrm{g} / \mathrm{kg} \mathrm{P}^{0,75}\right)$ & 100,35 & 100,99 & 105,40 & 11,12 \\
\hline
\end{tabular}

Valores de CMSF e CMST não diferem entre si, independente do modo de expressar o consumo.

$\mathrm{SM}=$ suplemento mineral; SUP1 = suplementação de $0,17 \%$ do peso vivo médio de ingestão; SUP2= suplementação de $0,37 \%$ do peso vivo médio de ingestão. $\mathrm{CV}(\%)=$ coeficiente de variação.

Quanto ao desempenho dos novilhos (Tab. 6), o efeito da covariável peso inicial não foi significativo. As diferenças de GMD entre os tratamentos SM e SUP1 foram de $0,120 \mathrm{~kg} / \mathrm{cabeça} / \mathrm{dia}$ e de $0,211 \mathrm{~kg} / \mathrm{cabeça} / \mathrm{dia}$ entre SM e SUP2. Estes valores são próximos aos citados por Paulino et al. (2002a), que observaram acréscimos de GMD de 0,2 a $0,3 \mathrm{~kg} /$ cabeça $/$ dia para a suplementação, durante a época das águas. Resultados semelhantes quanto à resposta à suplementação protéica foram encontrados por Zervoudakis et al. (2000), ao suplementarem novilhas com 200g de PB por dia em pastagens de $B$. brizantha cv. Marandu, com média de $10 \%$ de $\mathrm{PB}$. A resposta à suplementação protéica foi $193 \mathrm{~g}$ a mais em ganho médio diário de peso em comparação ao suplemento mineral e os resultados foram de 
0,$708 ; 0,883 ; 0,920 \mathrm{~kg} /$ novilha para suplemento mineral, suplemento com milho e farelo de glúten de milho e suplemento com milho e farelo de soja, respectivamente $(\mathrm{P}<0,05)$. Os resultados em ganho em peso foram mais altos que os deste experimento.

Tabela 6. Médias de peso vivo inicial (PVI), peso vivo final (PVF), ganho médio total (GMT), ganho médio diário (GMD) e consumo médio de suplemento (CS), de acordo com os tratamentos

\begin{tabular}{lcccc}
\hline & SM & SUP1 & SUP2 & CV $(\%)$ \\
\hline PVI (kg) & 219 & 209 & 206 & 19,62 \\
PVF (kg) & 275 & 277 & 284 & 16,69 \\
GMT (kg/cabeça)* & $56,1 \mathrm{~b}$ & $68,8 \mathrm{a}$ & $78,3 \mathrm{a}$ & 19,90 \\
GMD (kg/cabeça/dia)* & $0,535 \mathrm{~b}$ & $0,655 \mathrm{a}$ & $0,746 \mathrm{a}$ & 19,91 \\
\hline CS (kg/cabeça/dia) & 0,034 & 0,421 & 0,900 & \\
CS (\% peso vivo médio) & 0,01 & 0,17 & 0,37 & \\
\hline
\end{tabular}

Médias de ganho de peso seguidas por letras distintas na mesma linha diferem entre si $(\mathrm{P}<0,05)$.

Os consumos de forragem, suplementos, proteína bruta e NDT são mostrados na Tab. 7. A suplementação protéico-energética resultou em maior ingestão de proteína, principalmente, e energia, o que proporcionou ganhos médios diários mais elevados $(\mathrm{P}<0,05)$ em relação à suplementação só com mineral, mas não ocorreu diferença significativa entre os dois níveis de suplementação protéico-energética.
Considerando que um novilho com PV de $250 \mathrm{~kg}$, não castrado e cruzado, com ganho médio diário de $0,7 \mathrm{~kg}$ exige $0,65 \mathrm{~kg}$ de $\mathrm{PB}$ e $2,99 \mathrm{~kg}$ de NDT (Silva et al., 2002), os valores de PB, encontrados neste trabalho, são próximos. Entretanto, os valores de NDT foram 8,7 e $17,4 \%$ mais elevados para a SUP1 e SUP2, respectivamente, quando comparados com a exigência.

Tabela 7. Médias, com base na matéria seca, de consumo de forragem, suplemento, proteína bruta (PB) e de nutrientes digestíveis totais (NDT) (kg/cabeça/dia), de acordo com os tratamentos

\begin{tabular}{lccc}
\hline & SM & SUP1 & SUP2 \\
\hline Consumo médio de forragem (kg/cabeça/dia)1 & 6,40 & 5,91 & 5,73 \\
Consumo médio de suplemento (kg/cabeça/dia) & 0,034 & 0,363 & 0,779 \\
Consumo médio de PB (kg/cabeça/dia)2 & $0,440 \mathrm{~b}$ & $0,658 \mathrm{a}$ & $0,699 \mathrm{a}$ \\
Consumo médio de NDT (kg/cabeça/dia)2 & 3,23 & 3,25 & 3,51 \\
\hline
\end{tabular}

${ }^{1}$ Médias de consumo baseado no peso vivo médio de cada tratamento multiplicado pelo valor de consumo (\% PV) da Tab. 5. ${ }^{2}$ Foram usados os valores médios de PB e NDT da forragem da Tab. 4.

Valores seguidos por letras distintas na mesma linha diferem entre si $(\mathrm{P}<0,05)$.

Há diferenças estatísticas de ganho médio diário quando se comparam a suplementação protéica com a suplementação mineral, durante a época das águas. Alcalde et al. (2002) forneceram a novilhos um suplemento com $41 \% \mathrm{~PB}$, cujo consumo médio diário foi de $0,810 \mathrm{~kg}$ por cabeça/dia, em pastagens de $B$. brizantha cv. Marandu, com média 6,7\% de PB. Esses autores encontraram maior ganho em peso diário com a suplementação protéica em relação ao suplemento mineral, 1,064 e $0,725 \mathrm{~kg} /$ cabeça $(\mathrm{P}<0,05)$, respectivamente. Oliveira et al. (2003) também verificaram ganho médio diário mais elevado para a suplementação protéica, comparada à suplementação mineral. Os valores foram $0,497,0,563,0,601 \mathrm{~kg} /$ cabeça para suplementação mineral, suplementação de $0,8 \mathrm{~kg}$ da mistura múltipla de chuvas (MMC) e suplementação de $1,0 \mathrm{~kg}$ de $\mathrm{MMC}$, respectivamente. Também não encontraram diferenças significativas em relação ao ganho médio diário entre as suplementações protéicas, em pastagens de $B$. brizantha $\mathrm{cv}$. Marandu.

Trabalhos que utilizaram outras gramíneas também mostraram maior ganho médio diário de bovinos que consumiram suplementos protéicoenergéticos, com acréscimos médios variando de 0,07 a $0,378 \mathrm{~kg} /$ cabeça/dia, comparados à suplementação mineral, durante a época das águas (Villela et al. 2003; Peres et al., 2005).

Os resultados, às vezes, são contraditórios. Tomich et al. (2002) relataram ganhos médios 
diários de 0,599 e 0,628kg/cabeça, para bovinos que consumiram suplemento mineral e mistura múltipla (MM), respectivamente, em pastagens de $B$. brizantha e B. ruziziensis. O consumo da MM foi de 168 gramas/cabeça/dia e de 30 gramas/cabeça/dia de PB. Paulino et al. (2002b) não encontraram diferenças significativas de ganho médio diário de bovinos, em pastagens de B. decumbens Stapf, com média de 11,7\% de PB, suplementados com três suplementos diferentes, com $41 \%$ de PB e consumo médio de $526 \mathrm{~g} / \mathrm{cabeça/dia.} \mathrm{Os} \mathrm{resultados} \mathrm{de} \mathrm{ganho} \mathrm{médio}$ diário foram de 1,16, 1,29, 1,38 e 1,16kg/cabeça, para suplemento mineral, suplemento com milho e uréia, milho desintegrado com palha e sabugo e uréia, sorgo e uréia, respectivamente.

\section{CONCLUSÕES}

Pode-se recomendar a suplementação protéicoenergética para bovinos criados em pasto, pois o ganho de peso desses animais suplementados é maior do que o observado para os que só consomem suplemento mineral, na época de transição entre o período das águas e da seca.

\section{REFERÊNCIAS BIBLIOGRÁFICAS}

ALCALDE, C.R.; GARCIA, J.; ANDRADE, P. et al. Suplementação protéica em pastagens de "Brachiaria brizantha" no período das águas. In: REUNIÃO ANUAL DA SOCIEDADE BRASILEIRA DE ZOOTECNIA, 39., 2002, Recife. Anais ... Recife: SBZ, 2002. CD-ROM.

ALMEIDA, R.G.; EUCLIDES, V.P.B.; NASCIMENTO JUNIOR, D. et al. Consumo, composição botânica e valor nutritivo da dieta de bovinos em pastos tropicais consorciados sob três taxas de lotação. Rev. Bras. Zootec., v.32, p.29-35, 2003.

CATON, J.S.; DHUYVETTER, D.V. Influence of energy supplementation on grazing ruminants: requirements and responses. J. Anim. Sci., v.75, p.533-542, 1997.

EUCLIDES， V.P.B.; MACEDO, M.C.M.; OLIVEIRA, M.P. Avaliação de diferentes métodos de amostragem para se estimar o valor nutritivo de forragens sob pastejo. Rev. Bras. Zootec., v.21, p.691-702, 1992.
EUCLIDES, V.P.B. Alternativas para intensificação da produção de carne bovina em pastagem. Campo Grande: Embrapa Gado de Corte, 2000. 65p.

EUCLIDES, V.P.B.; CARDOSO, E.G.; MACEDO, M.C.M. et al. Consumo voluntário de Brachiaria decumbens cv. Basilisk e Brachiaria brizantha cv. Marandu sob pastejo. Rev. Bras. Zootec., v.29, supl.2, p.2200-2208, 2000.

HALL, M.B. Neutral detergent-soluble carbohydrates: nutritional relevance and analysis, a laboratory manual. Gainesville: University of Florida Extension Bulletin, 339. 2000 .

McMENIMAN, N.P. Methods of estimating intake of grazing animals. In: SIMPÓSIO SOBRE TÓPICOS ESPECIAIS EM ZOOTECNIA, 1997, Juiz de Fora. Anais ... Juiz de Fora : SBZ, 1997. p.133-168.

NUTRIENT requeriments of beef cattle. 7.ed. Washington: National Academy of Sciences, 1996. 242p.

OLIVEIRA, L.O.F.; AMARAL, T.B.; SALIBA, E.S. et al. Desempenho de novilhos Nelore suplementados com misturas múltiplas dos 8 aos 26 meses de idade. In: REUNIÃO ANUAL DA SOCIEDADE BRASILEIRA DE ZOOTECNIA, 40., 2003. Santa Maria. Anais... Santa Maria: SBZ, 2003. CD-ROM.

PAULINO, M.F.; ZERVOUDAKIS, J.T.; DE MORAES, E.H.B.K. et al. Bovinocultura de ciclo curto em pastagens. In: SIMPÓSIO DE PRODUÇÃO DE GADO DE CORTE, 3., 2002, Viçosa. Anais... Viçosa: UFV. 2002a. p.153-196.

PAULINO, M.F.; DE MORAES, E.H.B.K.; ZERVOUDAKIS, J.T. et al. Suplementação de novilhos mestiços recriados em pastagens de Brachiaria decumbens durante o período das águas: desempenho. In: REUNIÃO ANUAL DA SOCIEDADE BRASILEIRA DE ZOOTECNIA, 39., 2002, Recife. Anais... Recife: SBZ, 2002b. CD-ROM.

PERES, A.A.C.; VASQUEZ, H.M.; SILVA, J.F.C et al. Avaliação produtiva e econômica de sistemas de produção bovina em pastagens de capim-elefante. Arq. Bras. Med. Vet. Zootec., v.57, p.367-373, 2005. 
PORDOMINGO, A.J.; WALLACE, J.D.; FREEMAN, A.S. et al. Supplemental corn grain for steers grazing native rangeland during summer. J. Animal Sci., v.69, p.1678-1687, 1991.

SILVA, D.J.; QUEIROZ, A.C. Análise de alimentos: métodos químicos e biológicos. 3.ed. Viçosa: UFV, 2002. 235p.

SILVA, F.F.; VALADARES FILHO, S.C.; ÍTAVO, L.C.V. et al. Exigências líquidas e dietéticas de energia, proteína e macroelementos minerais de bovinos de corte no Brasil. Rev. Bras. Zootec., v.31, p.776-792, 2002.

SMITH, A.M.; REID, J.T. Use of chromic oxide as an indicator of fecal output for the purpose of determining the intake of a pasture herbage by grazing cows. J. Dairy Sci., v.38, p.515-524, 1955 .

TILLEY, J.M.A.; TERRY, R.A. A two-stage technique for the in vitro digestion of forage crops. J. Br. Grassl. Soc., v.18, p.104-111, 1963.

TOMICH, T.R.; LOPES H.O.S.; PIRES, D.A.A. et al. Suplementação com mistura múltipla contendo uréia como fonte de nitrogênio para bovinos em pastagens de braquiária no período das águas. In: REUNIÃO ANUAL DA SOCIEDADE BRASILEIRA DE ZOOTECNIA,
39., 2002, Recife. Anais... Recife: SBZ, 2002. CD-ROM

USER'S guide: statistics. Version 6, 4.ed. Cary, NC: SAS Institute, 1990.

VAN SOEST, P.J. Nutritional ecology of the ruminant. 2.ed. Ithaca: Cornell University, 1994. 476p.

VILLELA, S.D.J.; PAULINO, M.F.; VALADAES FILHO, S.C. et al. Efeito da suplementação com diferentes fontes de proteína para bovinos de corte em pastejo no período das águas. 1- desempenho. In: REUNIÃO ANUAL DA SOCIEDADE BRASILEIRA DE ZOOTECNIA, 40., 2003, Santa Maria. Anais... Santa Maria: SBZ, 2003. CD-ROM.

WILLIAMS, C.H.; DAVID, D.J.; ISMAA, O. The determination of chromic oxide in faeces samples by atomic absortion spectrophotometry. J. Agric. Sci., v.59, p.381-385, 1962.

ZERVOUDAKIS, J.T.; PAULINO, M.F.; DETMANN, E. et al. Desempenho de novilhas mestiças suplementadas durante o período das águas. In: REUNIÂO ANUAL DA SOCIEDADE BRASILEIRA DE ZOOTECNIA, 37., 2000, Viçosa. Anais... Viçosa: SBZ, 2000. CD-ROM. 